\title{
Evaluation of the inactivation effect of riboflavin photochemical method on duck hepatitis B virus
}

\author{
ZI-YU ZHOU and XING-XIU BI \\ Xuzhou Red Cross Blood Station, Xuzhou, Jiangsu 221006, P.R. China
}

Received June 14, 2017; Accepted October 10, 2017

DOI: $10.3892 /$ etm.2017.5507

\begin{abstract}
Hepatitis B virus (HBV) is a common and widespread infection that poses a serious threat among carriers for the development of life-threatening liver diseases. The aim of the present study was to evaluate the effectiveness of the riboflavin photochemical method in inactivating duck hepatitis B virus (DHBV) in plasma via an animal model. Forty ducks were selected and randomly divided into the experimental $(n=10)$, the virus control $(n=10)$, the visible light control $(n=10)$ and the plasma control group $(n=10)$. Ducks in the experimental group were injected with plasma inactivated by the riboflavin photochemical method; in the virus control group were injected with plasma without inactivation treatment; in the visible light control group were injected with plasma irradiated by visible light; and in the plasma control group were injected with normal plasma. The serum of the ducks in each group was taken at different time points to detect DHBV-DNA levels via FQ-PCR and duck hepatitis B surface antigen (DHBsAg) via ELISA. DHBV-DNA in the experimental group was decreased gradually over time until it disappeared and there was a significant difference in DHBsAg between the experimental and control groups $(\mathrm{P}<0.05)$. In conclusion, the results showed that the riboflavin photochemical method is effective in the inactivation of viruses in plasma, which has relevance for preventive strategies against transfusion-derived infections.
\end{abstract}

\section{Introduction}

HBV (hepatitis B virus) is a common virus that poses a serious threat to humans. and the hepatic failure, liver cirrhosis and primary hepatocellular carcinoma caused by HBV infection are extremely harmful to human health (1). There are many reports of patients infected with hepatitis B due to HBV contained in blood samples, resulting in great harm to

Correspondence to: Dr Xing-Xiu Bi, Xuzhou Red Cross Blood Station, 128 Xi'an South Road, Xuzhou, Jiangsu 221006, P.R. China E-mail: 309019085@qq.com

Key words: riboflavin/photochemical method, viral inactivation, plasma, animal model, duck hepatitis B virus the patients and their families (2). However, with ongoing developments in socioeconomics and improvements in the medical field, advancements such as blood transfusion therapy have made a great contribution to reducing morbidity from viral illness. As such, an increasing number of researchers have investigated viral inactivation techniques, including that of the riboflavin photochemical method.

The riboflavin photochemical method has previously drawn widespread attention in the field of inactivation of pathogenic microorganisms in blood components. Its effectiveness and safety have been scientifically confirmed (3). The principle of inactivation is that riboflavin binds to viral DNA/RNA to oxidize guanine residues on nucleic acid chains while under the activation of ultraviolet/visible light, thereby forming covalent bonds that mediate the rupture of nucleic acid backbone chains. This rupture of the nucleic acid prevents the replication, transcription and translation of viral nucleic acid, thus inactivating the virus (4). To evaluate its effectiveness, a cell infection method is often used; that is, the corresponding host cell is infected with the virus to observe the cytopathic effect in order to indirectly simulate and observe the viral inactivation effect (5). Both duck hepatitis B virus (DHBV) and HBV belong to the hepatotropic DNA virus family, and the nucleic acid composition, biological characteristics and pathogenesis of DHBV are similar to those of HBV. For this reason, ducks infected with DHBV were used as an animal model to study HBV infection and pathogenesis (6).

The aim of the present study was to evaluate the effectiveness of riboflavin photochemical method in the inactivation of DHBV with visible light as a control.

\section{Materials and methods}

Main reagents and instruments. DHBV seeds were provided by Xuzhou Medical College (Xuzhou, China). Protease K, Taq DNA polymerase, PCR buffer, dNTP mixture and $\mathrm{MgCl}_{2}$ were the products of Sangon Biological Engineering Technology \& Services Co., Ltd. (Shanghai, China). Riboflavin sodium phosphate was the product of Sigma-Aldrich (St. Louis, MO, USA). Duck hepatitis B surface antigen (DHBsAg) kit, microplate reader, and a microplate washer were provided by (Biosharp, Hefei, China). Blood was provided by the Xuzhou Blood Center (Xuzhou, China). A viral inactivation cabinet was sourced from Zibo Zhongbaokang Medical Equipment Co., Ltd. (Shandong, China). Quantitative fluorescence-polymerase chain reaction 
(QF-PCR) amplifier and nucleic acid protein detector were sourced from Bio-Rad Laboratories (Hercules, CA, USA).

Preparation of virus-containing plasma and viral inactivation treatment. Fresh whole blood $(5 \mathrm{ml})$ was extracted from the ducks of each group and was centrifuged for $10 \mathrm{~min}$ at $3,000 \mathrm{xg}$ at $4^{\circ} \mathrm{C}$ to separate the plasma. The plasma was then packed into $50 \mathrm{ml}$ blood bags $(10 \mathrm{ml} / \mathrm{bag})$. DHBV seeds were added into the plasma of the experimental, visible light control and virus control groups for a final concentration of $10^{8} \mathrm{cp} / 250 \mu \mathrm{l}$. The experimental group received riboflavin sodium phosphate at a final concentration of $300 \mu \mathrm{mol} / 1$ and irradiation of visible light at an irradiance of 40,000 lux (wavelength: 400-500 nm) for $30 \mathrm{~min}$. The visible light control group only received irradiation of visible light with an irradiance of 40,000 lux for $30 \mathrm{~min}$ and without the addition of riboflavin sodium phosphate. The virus control group received riboflavin sodium phosphate at a final concentration of $300 \mu \mathrm{mol} / 1$ and without light treatment, being placed in the dark for $30 \mathrm{~min}$. In addition, the plasma control group did not receive riboflavin sodium phosphate and served as the control, and was placed in the dark for $30 \mathrm{~min}$. The above four groups of experiments were performed on a low-temperature operating desk set at $4 \pm 2^{\circ} \mathrm{C}$.

Experimental animal grouping. Sixty Tianfu ducks aged 1 day were purchased from the Jiangsu Ecological Poultry Incubation Base (Jiangsu, China). After the sterile collection of venous blood from the ducklings, the serum was separated and screened for experimentation using a DHBV DNA probe via dot hybridization. Forty ducklings without DHBV were then divided into 4 groups, with 10 ducks in each group. Ducks in the experimental group $(n=10)$ were injected via tibial veins with the viral plasma treated with riboflavin photochemical method $(0.25 \mathrm{ml} / \mathrm{duck})$. Ducks in the virus control group $(\mathrm{n}=10)$ were injected via tibial veins with the viral plasma and with only riboflavin sodium phosphate added $(0.25 \mathrm{ml} / \mathrm{duck})$. Ducks in the visible light control group $(n=10)$ were injected via tibial veins with the viral plasma and were only treated with visible light $(0.25 \mathrm{ml} / \mathrm{duck})$. Ducks in the plasma control group $(\mathrm{n}=10)$ were injected via tibial veins with the plasma but without DHBV $(0.25 \mathrm{ml} / \mathrm{duck})$. The blood was collected from the wing veins each time during follow-up. Serum DNA was extracted according to the instructions of the kit and the serum DHBV DNA levels were detected via QF-PCR. The study was approved by the Ethics Committee of Xuzhou Red Cross Blood Station (Xuzhou, China).

QF-PCR detection of DHBV nucleic acid. Blood was drawn from the ducks and the DNA was extracted for QF-PCR amplification according to the instructions of the virus DNA extraction kit. Standard plasmid $(2 \mu \mathrm{l})$ containing DHBV wholegenome or DNA samples were used as the template. Primers (sense: ACATACACCCCTCTCTCGAA-AG, and antisense: GGACAGTCACACACGACAACA), Taq DNA polymerase, PCR buffer, dNTP mixture, and $\mathrm{MgCl}_{2}$ were all added. The $\mathrm{C}_{\mathrm{q}}$ value and the copy number of viral nucleic acid were detected using the QF-PCR amplifier according to the standard curve. Reaction conditions were as follows: Pre-degeneration at $95^{\circ} \mathrm{C}$ for $1 \mathrm{~min}$, degeneration at $95^{\circ} \mathrm{C}$ for $5 \mathrm{sec}$, annealing at $51^{\circ} \mathrm{C}$ for $5 \mathrm{sec}$, and extension at $72^{\circ} \mathrm{C}$ for $30 \mathrm{sec}$, for a total of 40 cycles.
Three tubes were detected for each sample to be detected and the average was taken for each sample.

DHBsAg detection. Duck serum samples were obtained at 2, 7, 14, 21 and 28 days into the experiment and were assessed by qualitative detection via enzyme-linked immunosorbent assay (ELISA). The operation was performed with strict adherence to the instructions of the kit.

Statistical analysis. SPSS 20.0 software (IBM Corp., Armonk, NY, USA) was used for statistical analysis. The Student's t-test was used for the comparison of the means between two sample means and the Chi-square test was used for the comparison of the rates in enumeration data between groups. For each comparison, $\mathrm{P}<0.05$ was considered to indicate a statistically significant diference. The inspection level for type I error was set at $\alpha=0.05$.

\section{Results}

DHBV-DNA QF-PCR standard curve. The standard samples were detected via QF-PCR. The typical amplification curve appeared within the exponential region and there was a good linear correlation among the 6 points. The normal curve was $\mathrm{Y}(\mathrm{CT}$ value $)=-3.872 \mathrm{X}(\log$ value of copy number $)+48.879$. Therefore, the sample to be detected was accurately quantified according to the $\mathrm{C}_{\mathrm{q}}$ value and standard curve.

DHBV-DNA QF-PCR detection results. Under the assumption that the QF-PCR reaction system and conditions were consistent across tests, each group of samples was detected and the average $\mathrm{C}_{\mathrm{q}}$ value was calculated. The average $\mathrm{C}_{\mathrm{q}}$ value of each group was converted into the copy number via the standard curve $Y=-3.872 X+48.879$. The results are shown in Table I. The serum was extracted from each group of ducks at regular time intervals to detect DHBV DNA. No infection was evident in the plasma control group. There was a significant difference between the experimental group and the control groups $(\mathrm{P}<0.05)$. The copy number of the virus in the experimental group was significantly lower than that in the visible light control group and the virus control group following day 7 , and a decrease over time was evident in the copy number among the experimental group. There was no significant difference in copy numbers between the virus control and visible light control groups.

DHBsAg detection results. Detection of DHBsAg showed that there were no ducks with DHBsAg in the plasma control group. At 7, 14 and 21 days into the experiment, the number of ducks with DHBsAg in the experimental group was significantly smaller than that in the control groups, and there was a significant difference between groups $(\mathrm{P}<0.05)$. There was no significant difference in the proportion of ducks with DHBsAg between the two control groups ( $\mathrm{P}>0.05)$. Specific data on the results are shown in Table II.

\section{Discussion}

According to recent statistics, there are approximately 130 million HBV carriers in China and a considerable number 
Table I. Detection of serum DHBV-DNA in each group of ducks at different time points ( $\mathrm{n}=10$ for each group).

\begin{tabular}{|c|c|c|c|c|c|c|c|c|c|}
\hline \multirow{3}{*}{$\begin{array}{l}\text { Time } \\
\text { (days) }\end{array}$} & \multicolumn{9}{|c|}{ Groups } \\
\hline & \multicolumn{3}{|c|}{ Experimental } & \multicolumn{3}{|c|}{ Virus control } & \multicolumn{3}{|c|}{ Visible light control } \\
\hline & $\mathrm{C}_{\mathrm{q}}$ value & Log value & Copy no. & $\mathrm{C}_{\mathrm{q}}$ value & Log value & Copy no. & $\mathrm{C}_{\mathrm{q}}$ value & Log value & Copy no. \\
\hline 2 & $31.1 \pm 0.56^{\mathrm{a}}$ & 4.6 & $3.98 \mathrm{E}+04$ & $23.3 \pm 0.51$ & 6.6 & $3.98 \mathrm{E}+06$ & $23.7 \pm 0.48$ & 6.5 & $3.16 \mathrm{E}+0$ \\
\hline 7 & $37.6 \pm 0.62^{\mathrm{a}}$ & 3.2 & $1.58 \mathrm{E}+03$ & $15.9 \pm 0.42$ & 8.5 & $3.16 \mathrm{E}+08$ & $16.4 \pm 0.51$ & 8.4 & $2.51 \mathrm{E}+08$ \\
\hline 14 & $0^{\mathrm{a}}$ & 0 & 0 & $14.0 \pm 0.32$ & 9.2 & $1.58 \mathrm{E}+09$ & $13.3 \pm 0.41$ & 9.0 & $1 E+09$ \\
\hline 21 & $0^{\mathrm{a}}$ & 0 & 0 & $13.6 \pm 0.41$ & 9.3 & $1.99 \mathrm{E}+09$ & $12.9 \pm 0.40$ & 9.1 & $1.26 \mathrm{E}+09$ \\
\hline 28 & $0^{\mathrm{a}}$ & 0 & 0 & $15.6 \pm 0.51$ & 8.7 & $5.08 \mathrm{E}+08$ & $15.2 \pm 0.49$ & 8.6 & $3.98 \mathrm{E}+08$ \\
\hline
\end{tabular}

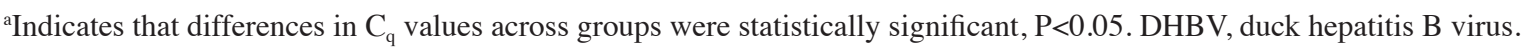

Table II. DHBsAg detection results of each group ( $\mathrm{n}=10$ for each group) at different time points.

\begin{tabular}{|c|c|c|c|c|c|c|}
\hline \multirow{3}{*}{$\begin{array}{l}\text { Time } \\
\text { (days) }\end{array}$} & \multicolumn{6}{|c|}{ Groups } \\
\hline & \multicolumn{2}{|c|}{ Experimental } & \multicolumn{2}{|c|}{ Virus control } & \multicolumn{2}{|c|}{ Visible light control } \\
\hline & Positive (no.) & Negative (no.) & Positive (no.) & Negative (no.) & Positive (no.) & Negative (no.) \\
\hline 7 & 0 & $10^{\mathrm{a}}$ & 8 & 2 & 8 & 2 \\
\hline 14 & 0 & $10^{\mathrm{a}}$ & 10 & 0 & 10 & 0 \\
\hline 21 & 0 & $10^{\mathrm{a}}$ & 10 & 0 & 10 & 0 \\
\hline
\end{tabular}

${ }^{\mathrm{a}}$ Indicates that the differences in rates of DHBsAg detection across groups were statistically significant, $\mathrm{P}<0.05$. DHBsAg, duck hepatitis B surface antigen.

of these HBV carriers are likely to develop chronic hepatitis, liver cirrhosis or primary hepatic carcinoma (7). HBV is mainly transmitted by blood or injection and it has become one of the major public health issues in China at the present time.

Although the application of new screening techniques has greatly improved the safety of blood transfusions, the likelihood of false negative due to an infection 'window phase' before serum antibody-positive conversion of blood donors constitutes a problem that cannot be ignored. The possibility of transfusion-derived diseases cannot be completely ruled out in clinical blood transfusion and, as such, there remains a risk of HBV infection due to transfusions (7). Previous findings have shown that an effective measure for reducing such a risk is by inactivating the possible viruses that may exist in blood and blood products (8). In China and other countries, cell infection methods and other in vitro experiments are used to evaluate the effectiveness of viral inactivation, and to assess whether the infectivity of a virus strain on host cells is decreased in vitro $(9,10)$. Although in vitro experimentation is an effective means of simulating viral infections in vivo, animal models are more sensitive than in vitro experiments. In the present study, we used a viral infection animal model, and injected the infected blood into the animal after viral inactivation treatment in order to evaluate the viral inactivation effect.
The results showed that the copy number of DHBV-DNA in ducks in the virus control group injected with the blood without treatment with the riboflavin photochemical method was significantly higher than that in the experimental group. The copy number in ducks injected with the blood treated by the riboflavin photochemical method was decreased gradually with the increase of time, indicating that there was still residual DHBV-DNA after treatment with the riboflavin photochemical method, albeit the DHBV has lost its infectivity and could be degraded after a certain period of time. The above results show that the duck infection status in the present study was consistent with the experimental design, indicating that the riboflavin photochemical method can effectively mediate the rupture of DHBV nucleic acid to inactivate the virus. Furthermore, it is evident that the single treatment with visible light does not have an obvious viral inactivation effect, which is consistent with our previous conclusion (11).

The evaluation of blood virus inactivation is divided into three parts: The effectiveness of the viral inactivation, the effect on blood functions and the residual toxicity of the treated blood. The present study and previous studies have shown that riboflavin-induced photochemistry can fully inactivate DHBV in plasma. However, whether the status of DHBV-infected ducks and DHBV-infected humans following treatment demonstrates the same clinical outcomes is worthy of investigation. The effects of riboflavin treatment on the 
function and viability of blood components and the safety and effectiveness prior to clinical application were not investigated in the present study due to limited experimental conditions, but remain avenues for further supplemental experimentation in the future.

\section{Acknowledgements}

The present study was supported by the Xuzhou Science and Technology Funds (grant no. XM13B051) and by the Jiangsu Blood Collecting and Supplying Organizations (grant no. JSCGX201512).

\section{References}

1. Lewandowska M and Piekarska A: New directions in hepatitis B therapy research. Clin Exp Hepatol 3: 119-126, 2017.

2. Githuku J and Ransom J: Transfusion transmissible infections among walk-in blood donors at Kisumu Regional Blood Transfusion Centre, Kisumu County, Kenya, 2015. Lab Med: Sep 23, 2017 (Epub ahead of print).

3. Zhou ZY and Bi XX: Experimental studies on the inactivation of HBV in blood via riboflavin photochemical treatment. Exp Ther Med 13: 222-224, 2017.

4. Mirshafiee H, Sharifi Z, Hosseini SM, Yari F, Nikbakht H and Latifi $\mathrm{H}$ : The effects of ultraviolet light and riboflavin on inactivation of viruses and the quality of platelet concentrates at laboratory scale. Avicenna J Med Biotechnol 7: 57-63, 2015.

5. Feys HB, Van Aelst B, Devreese K, Devloo R, Coene J, Vandekerckhove $\mathrm{P}$ and Compernolle V: Oxygen removal during pathogen inactivation with riboflavin and UV light preserves protein function in plasma for transfusion. Vox Sang 106: 307-15, 2014.
6. Zheng Q, Bai L, Zheng S, Liu M, Zhang J, Wang T, Xu Z, Chen Y, Li J and Duan Z: Efficient inhibition of duck hepatitis B virus DNA by the CRISPR/Cas9 system. Mol Med Rep 16: 7199-7204, 2017.

7. Corash L: Inactivation of viruses, bacteria, protozoa and leukocytes in platelet concentrates: current research perspectives. Transfus Med Rev 13: 18-30, 1999.

8. Roback JD, Conlan M, Drew WJ, Ljungman P, Nichols WG, and Preiksaitis JK: The role of photochemical treatment with amostosalen and UV-A light in the prevention of transfusiontransmitted cytomegalovirus infection. Transfus Med Rev 20: 45-56, 2006.

9. Cocca LHZ, Oliveira TMA, Gotardo F, Teles AV, Menegatti R, Siqueira JP, Mendonça CR, Bataus LAM, Ribeiro AO, Souza TFM, et al: Tetracarboxy-phthalocyanines: From excited state dynamics to photodynamic inactivation against bovine herpesvirus type 1. J Photochem Photobiol B 175: 1-8, 2017.

10. Li Q, Wang D, Yang D, Shan L and Tian P: Binding of Escherichia coli does not protect tulane virus from heat-inactivation regardless the expression of HBGA-Like Molecules. Front Microbiol 8: 1746, 2017.

11. Zhou ZY and Bi XX: Experimental studies on the inactivation of HBV in blood via ribofavin photochemical treatment. Exp Ther Med 13: 222-224, 2017.

This work is licensed under a Creative Commons Attribution-NonCommercial-NoDerivatives 4.0 International (CC BY-NC-ND 4.0) License. 